\title{
Natural Convection in an Enclosure with Discrete Roughness Elements on a Vertical Heated Wall
}

S. Shakerin (Colorado State University)

M. S. Bohn (SERI)

R. I. Loehrke (Colorado State University)

February 1986

Prepared for

8th International

Heat Transfer Conference

San Francisco, California

17-22 August 1986

Prepared under Task No. 3751.21

FTP No. 01-527-86

Solar Energy Research Institute

A Division of Midwest Research Institute

1617 Cole Boulevard

Golden, Colorado 8040 i-3393

Prepared for the

U.S. Department of Energy

Contract No. DE-AC02-83CH10093 


\section{NOTICE}

This report was prepared as an account of work sponsored by the United States Government. Neither the United States nor the United States Department of Energy, nor any of their employees, nor any of their contractors, subcontractors, or their employees, makes any warranty, expressed or implied, or assumes any legal liability or responsibility for the accuracy, completeness or usefulness of any information, apparatus, product or process disclosed, or represents that its use would not infringe privately owned rights.

\section{Printed in the United States of America Available from: \\ National Technical Information Service \\ U.S. Department of Commerce 5285 Port Royal Road \\ Springfield, VA 22161}

$\begin{array}{ll}\text { Price: } & \text { Microfiche } \\ \text { Printed Copy } & \text { A02 }\end{array}$

Codes are used for pricing all publications. The code is determined by the number of pages in the publication. Information pertaining to the pricing codes can be found in the current issue of the following publications. which are generally available in most libraries: Energy Research Abstracts, (ERA); Government Reports Announcements and Index (GRA and I); Scientific and Technical Abstract Reports (STAR); and publication, NTIS-PR-360 available from NTIS at the above address. 
NATURAL COYVECTION IN AN ENCLOSURE WITH DISCRETE ROUGHNESS

ELEMTRTS ON A VERTICAL HEATED HALL

S. Shakerin ${ }^{+}$, M. Bohn*, and R. I. Loehrke ${ }^{+}$

\section{ABSTRACT}

Natural convection flow next to a heated wall with single and repeated, two-dimensional, rectangular roughness elements is studied numerically and experimentally. The objective is to determine how these roughness elements influence heat transfer rates from the wall. Each roughness element consists of a thermally conducting, horizontal cylinder of rectangular cross section attached to the heated, isothermal wall of an enclosure. The height of roughness is on the order of the boundary layer thickness. Dye flow visualization in water confirms the numerical prediction that the steady flow over these elements does not separate. Only at high Rayleigh numbers, when the boundary layer below the roughness is unsteady, is local instantaneous flow reversal observed. Although steady flow reversals near the wall are not predicted or observed, nearly stagnant regions are formed, particularly between closely spaced cylinders. The surface heat flux in these stagnant regions is relatively low, so the total heat transfer rate may be nearly the same as for a smooth wall in spite of the increased surface area.

\section{NOHENCLATURE}

$\ell$

$\mathrm{Nu}_{\mathrm{L}}$

$\overline{\mathrm{Nu}}_{\mathrm{L}}$

$\mathrm{p}$
$\mathrm{P}$

Pr

II

qw aspect ratio $=\mathrm{H} / \mathrm{L}$

height of test cell

thermal conductivity

distance between heated and cooled surfaces in the test cell

height of roughness element

local Nusselt number =

. $q_{w} L / k\left(T_{H}-T_{C}\right)$

average Nusselt number =

$q_{w} L / k\left(T_{H}-T_{C}\right)$

distance along wall

length of heated surface

including roughness

Prandt 1 number

local heat flux
7

$q_{w}$

$\mathbf{R a}_{\mathrm{L}}$

S

$T_{i}=\frac{T_{H}+T_{C}}{2}$

$\mathrm{U}=\mathrm{uL} / \mathrm{a}$

$v=v L / a$

$\mathbf{x}$

$\mathrm{X}$

Y

Subscripts

C cooled wall

heated wall

1 lower roughness element

upper roughness element

Greek letters

a

B

thermal diffusivity

coefficient of thermal

expansion

$T-T_{i}$

$\frac{1}{T_{H}-T_{C}}$, dimensionless

temperature

kinematic viscosity

stream function,

$$
\frac{\partial \psi}{\partial y}=U, \frac{-\partial \Psi}{\partial x}=v
$$

\section{IATRODUCTION}

An understanding of natural convection heat transfer is essential for proper design of building energy systems, particularly for those buildings where passive heating and cooling techniques

+Mechanical Engineering Department, Colorado State University, Ft. Collins, C0, 80523.

* Solar Energy Research Institute, Golden, CO, 80401. 
are employed. Most of the past experimental and analytical work on natural convection heat transfer from surfaces has focused on smooth surfaces. However, the surfaces of buildings are seldom smooth. Based on the results of experiments and analysis in forced convection, one might anticipate that the roughness associated with surface texture and with isolated elements, such as window frames, may significantly influence the overall heat transfer rate from a wall. If this influence can be predicted with a reasonable degree of confidence, then surface treatment may become a design variable for heat transfer control. More fundamental data on the influence of surface roughness on heat transfer coefficients in natural convection are required to assess the magnitude of this effect.

Anderson and Bohn [1] identified two distinctly different ways that the natural convection heat transfer coefficient may be altered by roughness. The roughness may introduce disturbances into an overlying laminar boundary layer, which cause that boundary layer to prematurely undergo transition to turbulence. Thus, that part of the wall exposed to turbulent flow, which in absence of the roughness would have been in laminar flow, experiences heat transfer augmentation. Another way in which heat transfer may be altered is through various mechanisms associated with the locally altered flow near the roughness element. The heat transfer in fully separated zones may be reduced compared to that at the same location on a smooth surface. On the other hand, local flow acceleration in the attached regions and unsteady vortical flow originating in the unstable separated shear layer downstream of the roughness element may enhance heat transfer.

An early work in this area is that of Eckert et al. [2] who used smoke flow visualization to study the effect of a single, rectangular roughness element on the apparent position of transition on a vertical heated plate in air. They reported a decrease in the distance from the leading edge of the plate to the beginning of transition of up to $15 \%$ when an element with a height of about $3 / 4$ of the boundary layer thickness was added to a smooth plate.

The present work deals with the same fundamental roughness geometry but focuses on the flow and heat transfer processes in an enclosure in the immediate vicinity of single and repeated rectangular elements. Our interest in enclosures stems from the ultimate application mentioned earlier, building heat transfer. Due to stratification and flow recirculation in enclosures, results from classical vertical-plate-ininfinite-medium studies are not immediately applicable.

\section{APPROACH}

This study was carried out with complementary numerical and experimental efforts. Quantitative predictions were obtained over a range of parameters from the numerical part, while the qualitative checks on these predictions and on the validity of the two-dimensional model employed were provided by the experimental part.

\subsection{Numerical}

The unsteady, two-dimensional Boussinesq equations were solved for the flow in a rectangular enclosure. The equations for vorticity, stream function, and temperature were cast in finite-difference form using forward time differences, centered differences for the diffusive terms, and upwind differences for the convective terms. Each calculation started with the fluid isothermal and at rest. The two side walls were maintained at uniform, constant temperatures above and below the initial fluid temperature and the floor and ceiling of the enclosure were adiabatic. The calculations proceeded in time until steady-state conditions were achieved. A nonuniform, zonal mesh was used with grid points spaced more closely in the boundary layer and around the roughness element than in the core. The results were checked for grid independence and, for the case of smooth side walls, against a previously published "benchmark" solution (de Vahl Davis [3]), for enclosure flows. A detailed description of the numerical technique is contained in reference [4].

The roughness element height $\&$ (see Figure 1 for nomenclature) was chosen to be a multiple of the boundary layer thickness at the center of the smooth-walled enclosure at the same Rayleigh number. The boundary layer thickness was defined as the distance from the wall to the first zero crossing of the velocity profile. All of the numerical results presented here are for $\ell / \delta=1$; however, this study has been extended to $1 / 2 \leq \ell / \delta \leq 2$ and the results are qualitatively the same. Likewise, most of the results presented here are for an enclosure with aspect ratio $A=H / L=1, R a_{L}=10^{6}, \operatorname{Pr}=0.7$, but the study has included $L \leq A \leq 3,10^{5} \leq \operatorname{Ra}_{L} \leq 10^{8}$, and $\operatorname{Pr}=0.7$ and 7.0 with qualitatively the same results.

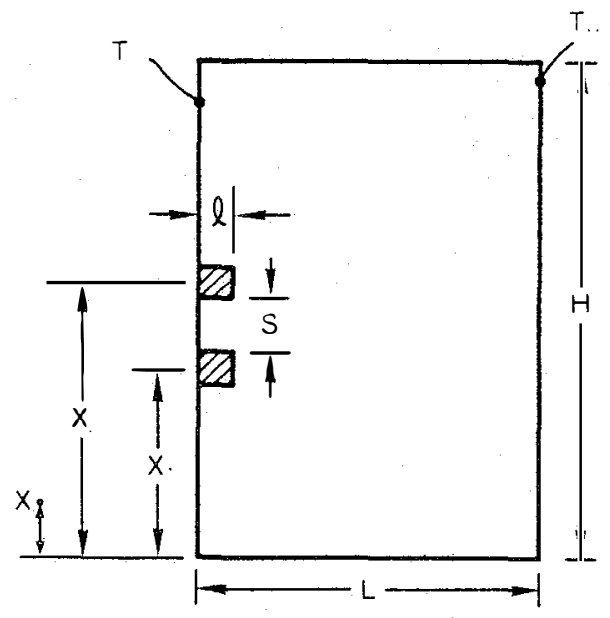

Figure 1. Nomenclature for enclosure with roughness elements on heated wall 


\subsection{Experimental}

Experiments were performed in two different test cells. Dye visualization of the flow over the roughness was carried out in a water-filled one-foot cubical test cell. Opposing, smooth vertical aluminum walls were heated and cooled to drive the flow. The other two vertical walls were made of lucite to permit viewing. The roughness elements for this test were $6.3-\mathrm{mm}-$ square aluminum rods that were glued to the heated wall using RTV silicone adhesive. The axis of each rod was horizontal, and the rod spanned the entire heated surface. Details of the test cell are presented in reference [5]. The floor of the test cell was insulated and the top was open to allow insertion of a $1.5-\mathrm{mm}-$ diameter dye injection probe. The temperature difference between the hot and cold walls was maintained at $14^{\circ} \mathrm{C}$ giving a Rayleigh number based on the test cell dimensions of $8.3 \times 10^{9}$.

The second experimental apparatus used in this study included an air-filled enclosure and a Mach-Zehnder interferometer with a 150-mmdiameter field of view. The opposing, active aluminum walls of the enclosure are $51 \mathrm{~cm}$ wide and $111 \mathrm{~cm}$ high and are separated by $31 \mathrm{~cm}$. The remaining surfaces of the enclosure are insulated lucite. Moveable optical windows, placed at opposite sides of the heated plate, expose the boundary layer to one of the interferometer beams. A detailed description of this apparatus is contained in reference [6]. For the purpose of the testing reported here the enclosure side walls (except for the windows) were insulated externally while the floor and ceiling were insulated internally. The internal rigid foam insulation reduced the height of the walls to $91 \mathrm{~cm}$, creating an enclosure with an aspect ratio of 3.0; the hot wall and cold wall of the enclosure were maintained at $40^{\circ} \mathrm{C}$ and $11^{\circ} \mathrm{C}$, respectively, yielding a Rayleigh number of $R a_{\mathrm{L}}=5.3 \times 10^{7}$ based in the span between the active plates.

The roughness elements for this test were 12.5-mm-square aluminum bar stock and attached to the heated wall with RTV silicone adhesive. The heated wall was maintained at a uniform temperature to within $\pm 0.5^{\circ} \mathrm{C}$ using individually controlled electric heater strips. Thermocouples attached to a roughness element indicated that heat conduction through the adhesive was sufficient to keep the element at the same temperature (within $\pm 0.5^{\circ} \mathrm{C}$ ) as the hot wall.

\section{RESULTS}

\subsection{Flow Field}

The flow fields around single and repeated roughness elements were studied numerically and experimentally in the water tank. Dye injection at the base of the heated wall showed that the flow, in absence of the roughness element, was steady in the lower half of the enclosure. Somewhat above the center of the wall the dye streak lines become sinusoidally distorted and rolled up into vortices before reaching the upper surface.
The flow over a single roughness placed at $\mathrm{X}_{1} / \mathrm{H}=1 / 4$ (see Figure 1 ) remained steady and two-dimensional. The local Rayleigh number at this position was $\mathrm{Ra}_{\mathrm{y}}=1.3 \times 10^{8}$. Dye injected into the boundary layter below the rod rose along the wall and followed the contour of the roughness. Separation, with reverse flow at the wall or at the surface of the roughness, was never observed in the experiments provided that the element was located where the flow over the smooth wall was steady. Instantaneous flow reversal and shedding from the rod were observed only when the flow approaching the rod was unsteady. Numerical calculations confirm the absence of flow reversal in steady state for elements attached to the wall of an enclosure. Instantaneous flow reversal above the roughness is predicted only at early times in the start-up transient.

The tenacious nature of the boundary layer is vividly demonstrated in the flow over two closely spaced elements. The flow with $\mathrm{S}=2 l$ is shown in Figure 2. In Figure $2 a$ the dye introduced near the wall below the elements follows the wall and indicates the unidirectional nature of the flow. The dye in Figure $2 b$ was introduced near the maximum velocity point and shows that the main flow dips in near the wall between the two elements. A similar set of streak lines is shown in Figure 3 for rods set at $S=\ell$. Here, the main flow bridges the gap between the rods but the flow inside the gap does not reverse.

Similar quantitative results from the numerical calculations are shown in Figure 4 for the flow in a square enclosure at $R_{a}=10^{6}$ for $S=2 l$ in Figure $4 a$ and $S=\ell$ in Figure $4 \mathrm{~b}$. The boundary layers are relatively thick, so the roughness elements are large. The flow in the entire enclosure is steady; the flow in the vicinity of the roughness is similar to that visualized in the water tank.

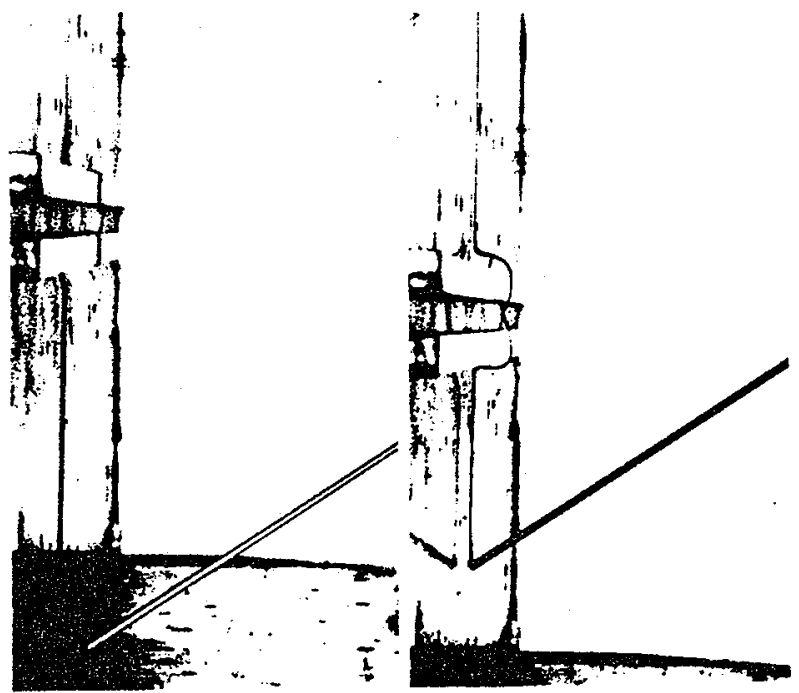

a. Dye injected near wall

b. Dye streak near velocity maximum

Figure 2. Dye visualization of flow over two bars; $\mathbf{S}=2 \ell$ 


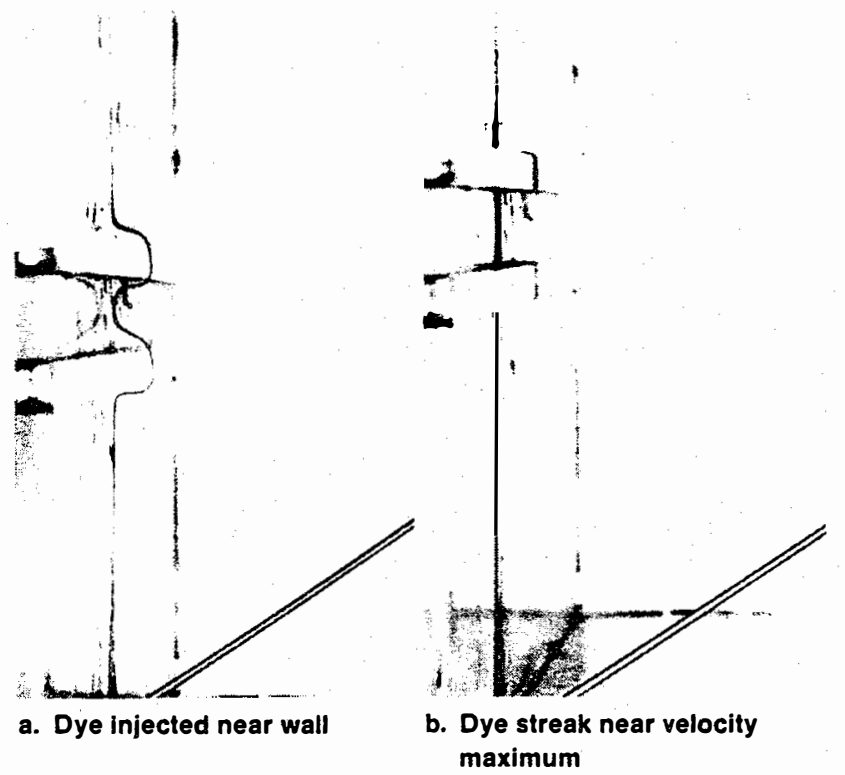

Figure 3. Dye flow visualization for two bars; $\mathbf{S}=\ell$

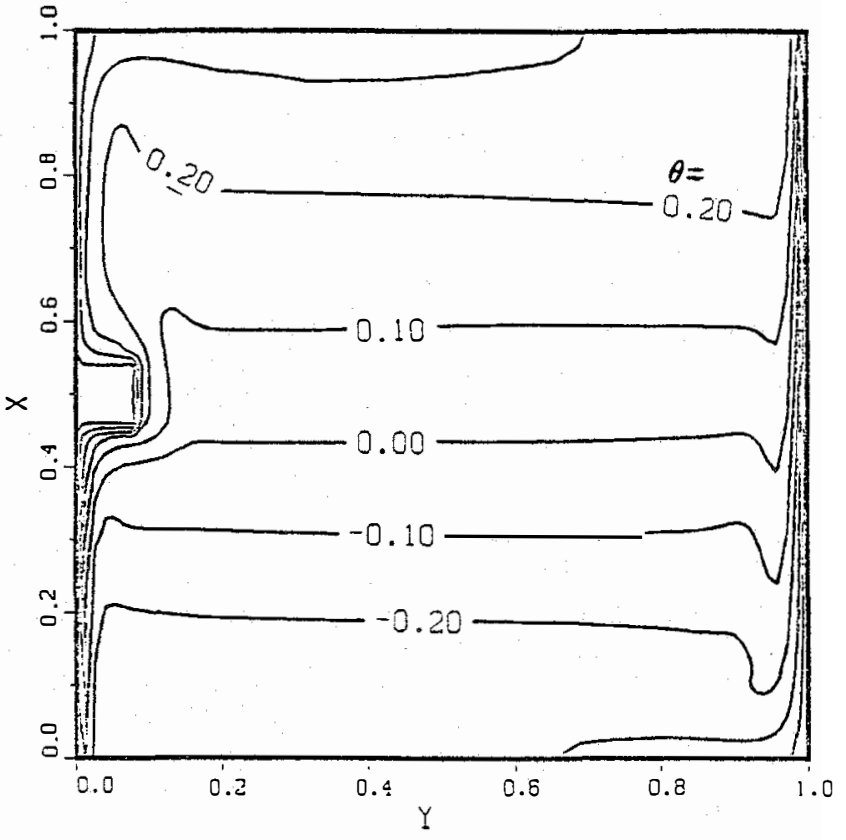

Figure 5. Calculated isotherms for flow over single roughness element in an enclosure; $A=1, R_{L}=10^{8}, \mathrm{Pr}=0.72$

wall of the air-filled enclosure is shown in the interferogram in Figure 6. This element is attached at $\mathrm{X}_{1} / \mathrm{H}=1 / 4$ so $R a_{\mathrm{X}_{1}}=2.2 \times 10^{7}$. Both the calculated and measured 1 isotherm patterns indicate that the surface heat flux is reduced along the wall just below and just above the

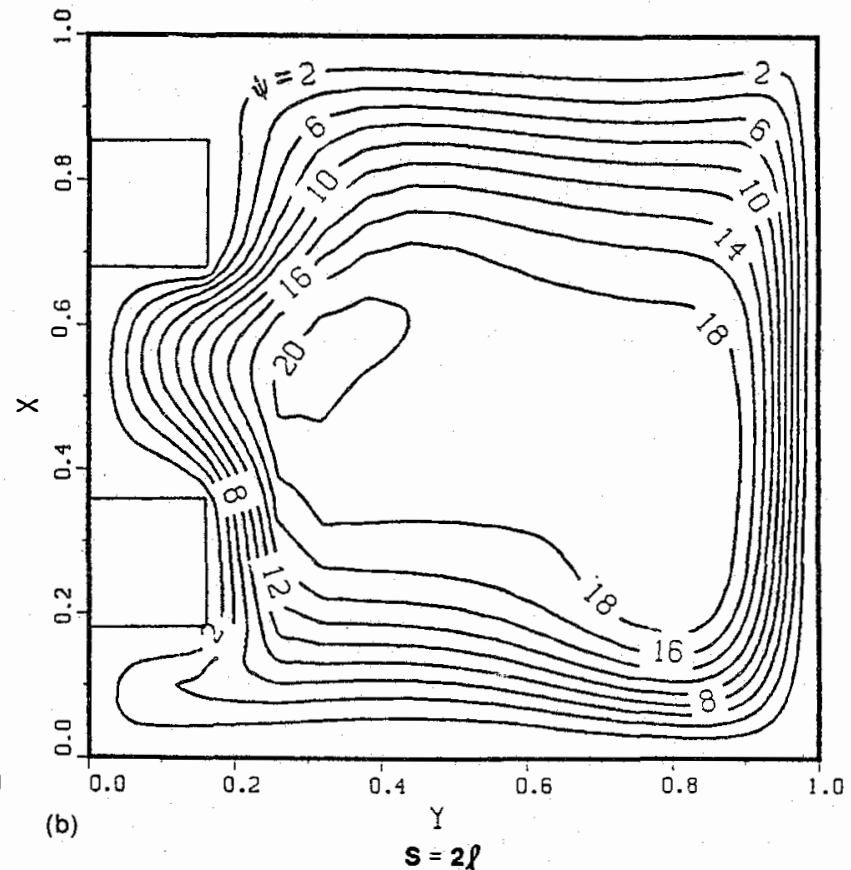

Figure 4. Calculated streamlines for flow over two roughness elements in an enclosure; $A=1$, $\mathrm{Ra}_{\mathrm{L}}=10^{6}, \mathrm{Pr}=0.72$ 
element compared with what it would be on a smooth wall. The temperature gradient at the outer surface of the element appears to be high, especially near the lower, outside corner.

These observations are quantified in Figure 7 , where the local Nusselt number, based on the calculated isotherms, is plotted as a function of position along the surface. The magnitude of the Nusselt number on the rough surface is indicated by the distance between the surface and the solid curved lines. The dashed line indicates the Nusselt number along the smooth wall at the same Rayleigh number. It can be seen that the influence of the roughness is mainly localized to within about two roughness heights above and below the roughness location. It also appears from this plot that the heat transferred through the extra surface area added by the roughness (the horizontal surfaces) should just about balance the reduction in heat transferred from the wall immediately below and above the element. This observation turns out to be roughly correct, as can be verified for $\mathrm{Ra}_{\mathrm{T}}=10^{\circ}$ by comparing the first two entries in Table 1. Here, the average Nusselt number $\overline{\mathrm{Nu}}$ over the entire heated surface is presented for several geometries. This Nusselt number is based on the total heat transfer rate from the heated surface and can therefore be used as a direct measure of this influence of the roughness on overall heat transfer from a surface. The increase in $\mathrm{Nu}$ shown in Table 1 , for a single roughness compared to a smooth wall is $12 \%$. This is much smaller than the $32 \%$ increase in surface area due to the addition of a single roughness at this Rayleigh number.

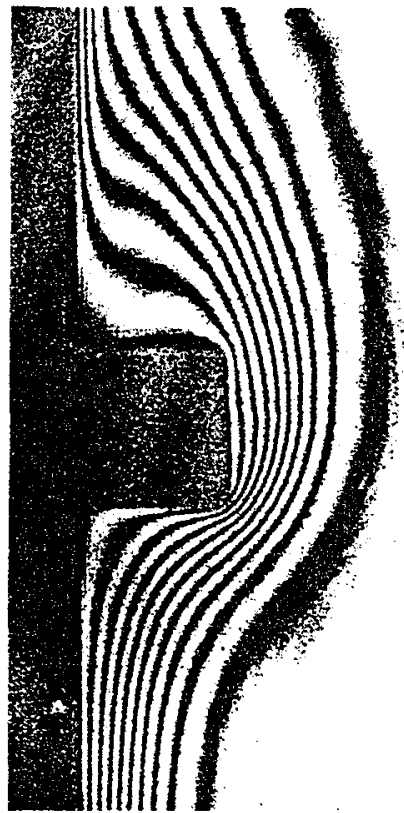

Figure 6. Interferogram showing isotherms around a single roughness element in an enclosure; $\mathrm{Ra}_{\mathrm{x}_{1}} 2.2 \times 10^{7}$,
$\mathrm{Pr}=0.71$

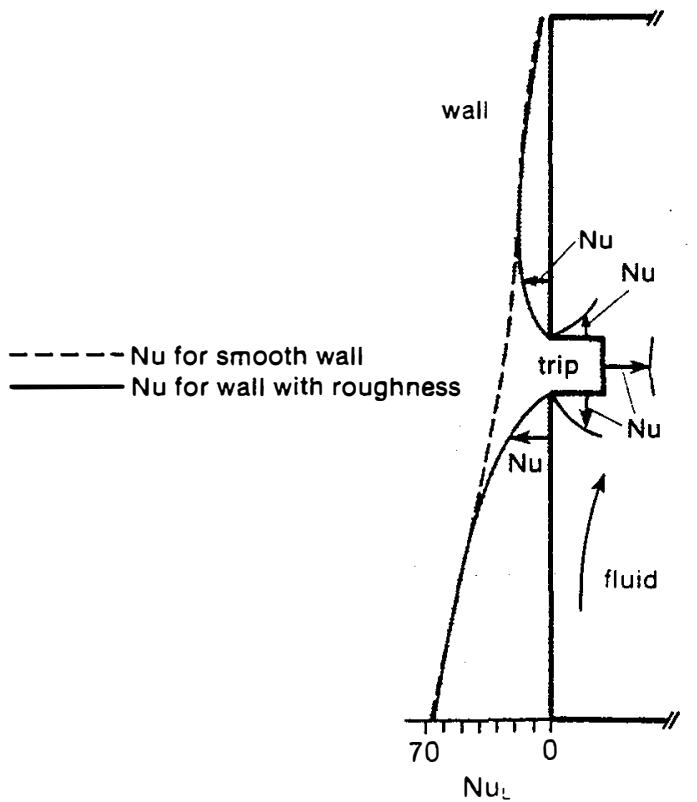

Eigure 7. Calculated local Nusselt number for flow on heated wall in an enclosure with and without a roughness element; $A=1, \mathrm{Ra}_{\mathrm{L}}=10^{8}, \mathrm{Pr}=0.72$

The interferograms for double roughness elements shown in Figure 8 indicate that for closely spaced elements the heat transfer from the surfaces that make up the cavity between the elements should be relatively low. Similar conditions are shown in Figure 9 for the calculated isotherms for two elements in an enclosure with $\mathrm{Ra}_{\mathrm{L}}=10^{6}$. The addition of a second roughness with $S=\ell$ results in no change in $\overline{\mathrm{Nu}}$ from that for a single roughness at $\mathrm{Ra}_{\mathrm{L}}=\mathrm{L}_{10^{6}}$. This can be verified by comparing the second and third entries in Table 1. If the spacing between the two elements is increased to $\mathrm{S}=2 \ell$, then $\overline{\mathrm{Nu}}$ increases slightly.

The average $\overline{\mathrm{Nu}}_{\mathrm{L}}$ for a single rectangular roughness element with an overall length (up the plate) equal to the sum of the two square roughness elements plus the gap between them is also shown in Table 1. The near equality of the average $\overline{N u}_{L}$ for the cases of two elements with $S=l$ and for the rectangular element with length $=3 \ell$ shows that at this close spacing the total heat transfer rate from the three surfaces of length $\ell$ forming the cavity between two roughness elements is essentially equal to that from a single surface of length $\ell$ positioned near the boundary layer.

\section{DISCUSSION AND CONCLUSIONS}

Eckert et al. [2] interpreted the existence of steady smoke streak lines over their obstacle as an indication that a flow-separation bubble existed with a steady laminar rotation within the separated flow region. This phenomenon was not 


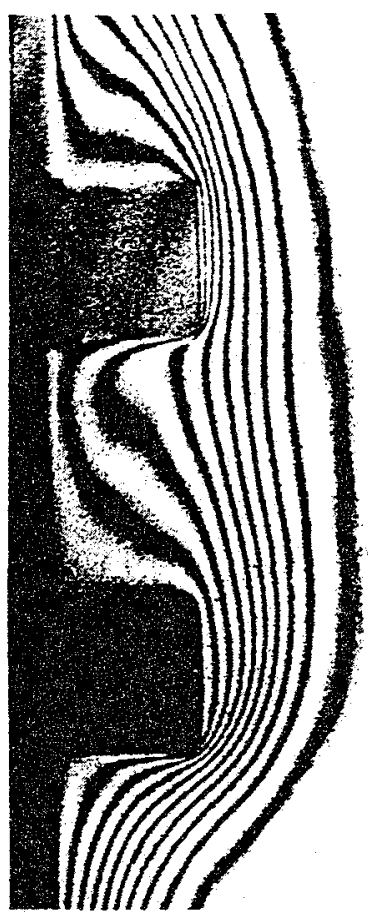

$S=2 \ell$

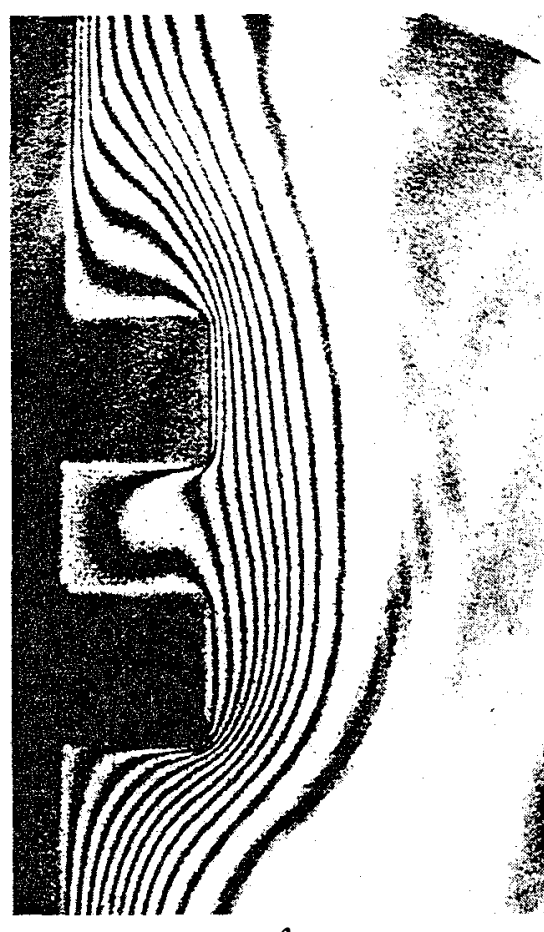

$s=\ell$

Figure 8. Interferograms for two roughness elements in an enclosure; $\mathrm{Ra}_{\mathrm{X}_{1}}=2.2 \times 10^{7}, \operatorname{Pr}=0.71$
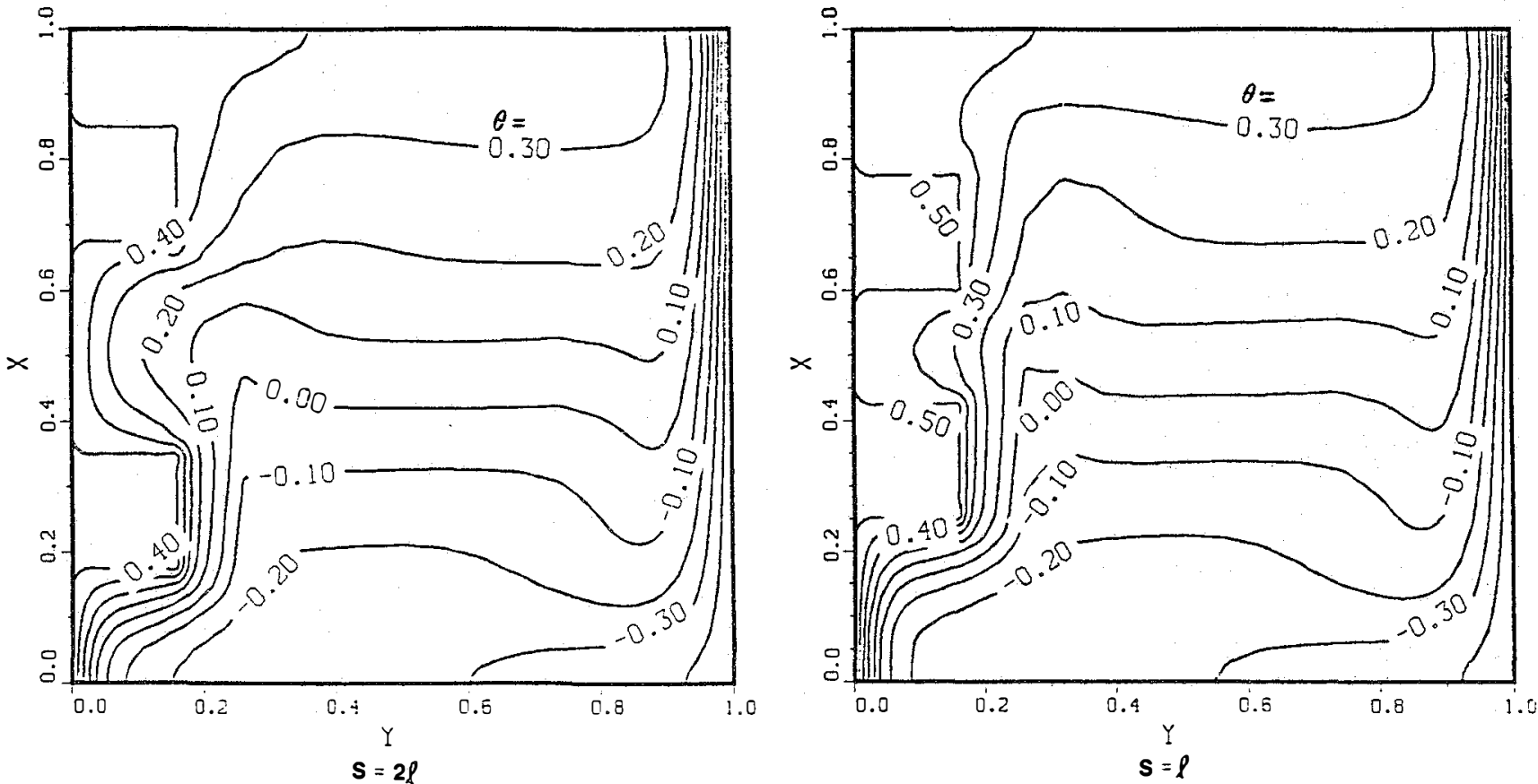

Figure 9. Calculated isotherms in an enclosure with two roughness elements; $A=1, R_{L}=10^{6}$, $\mathrm{Pr}_{\mathrm{r}}=0.72$ 
Table 1. Influence of geometry on the total heat transfer rate from the heated surface of an enclosure $\left(A=1 ; R a_{L}=10^{6}, \operatorname{Pr}=0.72\right)$

\begin{tabular}{lr}
\hline Geometry of Heated Surface & $\overline{\mathrm{Nu}}_{\mathrm{L}}$ \\
\hline Smooth surface & 9.2 \\
Single roughness & 10.3 \\
Double roughness & \\
$\quad \mathrm{S}=\ell$ & 10.3 \\
$\mathrm{~S}=2 \ell$ & 10.7 \\
Rectangular roughness & \\
$\quad$ length $=3 \ell$ & 10.2 \\
length $=4 \ell$ & 10.3 \\
\hline
\end{tabular}

observed in the present study: steady separation with reversal of wall shear stress was never observed in the two-dimensional flow over square rods. The steady natural convection boundary layers studied here tend to follow the wall contour very closely. The main boundary-layer flow skips over the gap between closely spaced roughnesses, but even here the slowly moving fluid between elements follows the main boundary layer. A recently published, two-dimensional, numerical study by Oosthuizen and Paul [7] indicates that this conclusion concerning the absence of separation may hold even for large surface interruptions that extend horizontally nearly from wall to wall. However, boundary layers flowing over large heated horizontal surfaces (or under cooled surfaces) are likely to become three-dimensional so the range of validity of these calculations needs to be further defined.

Heat transfer augmentation may be obtained in forced convection by placing a two-dimensional roughness element, such as one of the rods used in this study, in a laminar boundary layer. The highly unstable, separated shear layer created in the flow over a single rod undergoes rapid transition to turbulence and may augment heat transfer for a considerable distance downstream from the obstacle. The experiments reported here indicate that this mechanism for heat transfer augmentation is not so powerful in natural convection.

The effect of a roughness element on the downstream flow field and heat transfer wsis not studied in the present work. However, Eckert et al. [2] have concluded, on the basis of flow visualization, that the transition point may be displaced upstream by about $15 \%$ because of a twodimensional roughness. The influence of this displacement of the transition point on heat transfer needs further clarification.

Heat transfer may also be augmented by the addition of discrete roughness elements to a wall simply because the total surface area is increased. The results of the calculations reported here show that in laminar flow, a single horizontal bar is a poor $f$ in even if it is perfectly conducting. The gain caused by added surface area is just about cancelled by the reduction in heat transfer coefficient because of the turning of the boundary layer. With conducting, closely spaced, multiple roughness elements the total heat transfer is not significantly different from that for a smooth surface.

A reviewer of this paper brought to the authors' attention a related paper, Bhavnani and Bergles [8], which generally corroborates the findings of the present work.

\section{ACANOWLEDGRENTS}

Computer time on the CYBER 205 was generously provided by the Institute for Computational Studies at CSU. This work was partially funded by the Office of Solar Heat Technology of the U.S. Department of Energy as part of the Solar Buildings Technologies Program. The third author received support for participation in the experimental part of this work that was performed at SERI from the Associated Western Universities, Inc.

\section{REPERENCES}

1. Anderson, R., Bohn, M., Heat-Transfer Enhancement in Natural Convection Enclosure Flow, ASME Paper 84-Y-955. Accepted for publication in J. Heat Transfer.

2. Eckert, E.R.G., Hartnett, J.P., Irvine, T.F., Jr., Flow-Visualization Studies of Transition to Turbulence in Free-Convection Flow, ASME paper 60-WA-250, 1960.

3. de Vahl Davis, G., Natural Convection of Air in a Square Cavity: A Bench Mark Numerical Solution, Int. J. for Numerical Methods in Fluids, Vol. 3, Pp. 249-264, 1983.

4. Shakerin, S., Laminar Natural Convection on a Vertical Surface with Discrete Roughness, Ph.D. Thesis, Mechanical Engineering Dept., Colorado State University, 1986.

5. Bohn, M., Kirkpatrick, A., O1son, P., Experimental Study of Three Dimensional Natural Convection at High Rayleigh Numbers, J. Heat Transfer, Vol. 106, pp. 339-345, 1984.

6. Bohn, M., Fisher, E., Anderson, R., Development of an Interferometer for Natural Convection. Enhancement Research, SERI/PR-252-2598, Solar Energy Research Institute, Dec. 1985.

7. Oosthuizen, P. H., Paul, J. T., Free Convection Heat Transfer in a Cavity Fitted with a Horizontal Plate on the Cold Wall, Advances in Enhanced Heat Transfer--1985, Shenkman, S.M. et al., eds., ASME HTD Vol. 43, 1985.

8. Bhavnani, S., Bergles, A. E., Interferometric Study of Laminar Natural Convection from an Isothermal Plate with Transverse Roughness Elements, Ramachandran Festschrift Vol., Indian Society for Heat and Mass Transfer, Dec. 1985. 